\title{
"Ahora que estamos juntas": ciudadanías feministas y nuevos sensoriums en las agendas del Mundial Rusia 2018
}

"Now that we are together": feminist citizenships and new sensoriums in the agendas of the 2018 World Cup Russia

Mariana Elizabeth Ibarra marianaibarra@live.com http://orcid.org/0000-0002-5617-9201

Facultad de Humanidades; Universidad Nacional de Salta/ Consejo Nacional de Investigaciones Científicas y Técnicas (Argentina)

María Florencia Rodríguez florrodriguezunsa@gmail.com

http://orcid.org/0000-0001-8409-0530

Facultad de Humanidades; Consejo de Investigación; Universidad Nacional de Salta (Argentina) 


\title{
Resumen
}

A partir de los aportes teóricos-metodológicos de Jesús Martín Barbero y de los estudios de género, indagamos sobre las nuevas formas de ejercer ciudadanías desde el feminismo en una sociedad globalizada. Partimos de analizar la vinculación entre medios y miedos, a fin de comprender cómo esto genera mediaciones y procesos de resistencias en las nuevas formas de ejercer ciudadanía de las mujeres. En segunda instancia, nos focalizamos en cómo este movimiento global incide en la construcción de un nuevo sensorium que a su vez, tiene implicancias en la generación de nuevas identidades e imaginarios. Al respecto, analizaremos diferentes experiencias del último Mundial de Fútbol Rusia 2018. Por un lado, nos interesa deconstruir los sentidos más arraigados que restringen el fútbol de y para hombres y que en un evento de estas características, global, hipermediatizado y en las lógicas capitalistas, pretende instalar narrativas identitarias y nacionales restringidas a una cuestión pasional/despolitizada. Por otro, hacemos hincapié en las mediaciones que genera la lucha feminista en las calles y que, a partir de las nuevas tecnologías, permite configurar/deconfigurar nuevos sentidos, proponer otros relatos e historias para ejercer nuevas ciudadanías que incluyan y liberen a todos y todas.

Palabras clave: feminismo; ciudadanías; sensoriums; fútbol; mediaciones.

\begin{abstract}
Based on the theoretical-methodological contributions of Jesús Martin Barbero and gender studies, we inquired into new ways of exercising citizenship from feminism in a globalized society. We start by analyzing the link between the means and fears, in order to understand how this generates mediations and processes of resistance in the new ways to exercise women's citizenship. In the second instance, we focalize about how this global movement influences in the construction of a new sensorium that, in turn, has implications in generation of new identities and imaginaries. In this regard, we will analyze different experiences from the last football World Cup, Russia 2018. On the one hand, we are interested in deconstructing the most deeply rooted senses that restrict football only from and for men and that in an event of these characteristics, global, hyper mediated and in capitalist logics, it intends to install national narratives of identity and restricted to a passionate / depoliticized issue. On the other hand, we emphasize the mediations generated by the feminist struggle in the streets and, based on new technologies, this allow us to configure/deconfigure new meanings, to propose other stories to exercise new citizenships that include and free all people.
\end{abstract}


Keywords: Feminism; citizenship; sensoriums; football; mediations.

Los medios de comunicación masiva, en la actualidad, son herramientas fundamentales para el ejercicio de las ciudadanías a través de las diferentes expresiones que se manifiestan, especialmente, gracias a las nuevas tecnologías de la información y comunicación. Así pues, los paisajes culturales que configura la globalización, se convierten en lo que Appadurai (1991) define como "imágenes prototípicas" desde las cuales los y las sujetas se piensan y perciben. Dichas imágenes son generadoras de estereotipos que pujan por naturalizar desigualdades y opresiones. En este escenario, tiene lugar la vulneración de los derechos de las mujeres por la preponderancia del sexismo y la cosificación de sus cuerpos en los medios de comunicación a escala local, nacional y global. Sin embargo, como advierte Martín-Barbero (2000) los procesos de comunicación no pueden ser abordados y comprendidos únicamente desde los medios, es necesario, también, poner el lente de atención en aquellos movimientos sociales, como el feminismo, que interpelan identidades, territorios, imaginarios y subjetividades posibilitando nuevas formas de ejercer ciudadanías.

A partir de lo planteado, consideramos que, en un contexto de proliferación de nuevos medios y nuevas tecnologías, el autor propone reflexionar sobre cómo "la comunicación designa hoy un nuevo sensorium (Benjamin): nuevas sensibilidades, otros modos de percibir, de sentir y relacionarse con el tiempo y el espacio, nuevas maneras de reconocerse y de juntarse" (MartínBarbero, 1996: 11).

En este trabajo, nos interesa indagar en las nuevas formas de ejercer ciudadanías del feminismo en el contexto global a la luz de los aportes teórico-metodológicos de Jesús MartínBarbero. Para esto, en primer lugar, haremos referencia a la relación entre medios y miedos a fin de reflexionar cómo dicha tensión afianza mediaciones y resistencias en las nuevas formas de ejercer ciudadanías de las mujeres a través de experiencias de "imaginación social" (MartínBarbero, 2002). Posteriormente, analizaremos cómo este movimiento global promueve la generación de un nuevo sensorium de medios que interpela identidades e imaginarios. En este sentido, nos detendremos en diferentes situaciones acontecidas en el marco del último Mundial de Fútbol realizado en Rusia. 


\section{Las mujeres, entre los medios y los miedos: reflexiones sobre las mediaciones desde un enfoque de género}

Retomando algunas reflexiones de Martín-Barbero en el texto "La ciudad: entre medios y miedos", desde una perspectiva de género, entendemos que es importante interrogarse sobre aquellos miedos que enfrentamos las mujeres en la ciudad y sobre las características que este proceso asume en el marco de lo que el autor denomina "angustia cultural" (2000:32).

La incertidumbre y desconfianza a un otro o los otros (varones) en el marco del espacio público nutre la idea de que el cuerpo de las mujeres es un territorio que puede ser apropiado, insultado, humillado, etc. Esto es normalizado por la ciudad (Martín-Barbero, 2000) y exacerbado por los medios de comunicación que, en muchas ocasiones, presentan los hechos de abusos, violencia de género y/o femicidio desde el morbo y el sensacionalismo. Asimismo, un monitoreo de medios en Argentina sobre hechos de violencia contra adolescentes mujeres plantea que las coberturas periodísticas "parecen encasillar estos hechos como situaciones de inseguridad de la vida cotidiana o hechos aislados en lugar de contextualizar la violencia contra las mujeres como un problema cultural, sostenido por la desigualdad en la sociedad" (ELA, 2016).

A este contexto, se suma la normalización de esta concepción del cuerpo de las mujeres por parte de instituciones sociales que, muchas veces, exponen miradas machistas y misóginas en escenarios de comunicación masiva. Cabe mencionar, a modo de ejemplo, la situación que se vivenció en el marco de una conferencia de prensa protagonizada por el Director Técnico de la Selección Argentina, Jorge Sampaoli, tras la confirmación de la lista de convocados para jugar el mundial de Rusia 2018. Una periodista de la agencia AP realizó una pregunta refiriéndose a casos de violencia de género que se dieron en el marco del fútbol nacional, así lo describe textualmente Vilche (2018) en el portal web La Capital:

"En Argentina, a partir de 2015, se visibilizó la violencia de género con la campaña \#NiUnaMenos. En 2018, Argentina volvió a ser noticia por un manual de la AFA en el que se les contó a los hombres cómo seducir a las rusas, por una publicidad con un tono homofóbico, por un jugador incluido entre los preseleccionados que había sido denunciado por violencia de género, por una selección de fútbol femenino con escasos recursos que pide ser escuchada y por la salida a la luz de una red de pedofilia que capta jóvenes futbolistas. ¿No cree que el fútbol argentino se está quedando atrás respecto de los avances socioculturales de los últimos años? Sí, no y por qué. Gracias”. 
La interpelación de la periodista más allá de la figura del entrenador, se da en un territorio -el fútbol- en el que la violencia de género está totalmente invisibilizada y naturalizada. En efecto, la pregunta fue motivo de noticia y replicada en otros medios como "la pregunta polémica" (1), "la pregunta que descolocó" (2) y "la pregunta que incomodó" (3). Lejos de despertar un tratamiento sobre las problemáticas que iluminó la periodista, la cobertura se limitó a presentar la pregunta como un hecho disruptivo y a ironizar sobre los acotados esfuerzos de Sampaoli por realizar una autocrítica institucional. El entrenador utilizó la frase "vigilancia tecnológica" para referirse con total liviandad a las denuncias de violencia de género que visibilizaron las víctimas en las redes sociales, ignorando así los miedos expuestos por las mujeres en cada exposición pública.

De lo anterior, se revaloriza el planteo de Martín-Barbero (2000) de pensar la ciudad, en términos de procesos comunicacionales, a partir de la tensión que se establece entre medios y miedos. Para esto es necesario evitar dos cuestiones fundamentales: por un lado, no centrarnos solamente en los medios, sino también en las mediaciones que se producen en la intersección entre espacio público y espacio privado. Por otra parte, no debemos centrarnos en la cantidad de hechos delictivos para comprender los miedos sino indagar en sus orígenes.

Desde un enfoque de género, especialmente desde aquella frase que marcó la segunda ola feminista "lo personal es político" (4), las mujeres comenzaron a discutir la idea de circunscribir sus deseos, intereses y experiencias al ámbito privado partiendo de la premisa que aquella subordinación naturalizada era una cuestión política que debía expresarse en el espacio público. Aquí surgieron diferentes formas de interacción y comunicación entre las mujeres, siendo la movilización una de las formas de acción más visibles y recurrentes, especialmente en las ciudades. Esto muchas veces no aparecía en los medios de comunicación, pero fueron estas mediaciones la que permitieron el cuestionamiento del orden patriarcal. En términos de Virginia Guzmán (2018) (5) este proceso impulsó un periodo de institucionalización de demandas de género a través del planteo de agendas y cambios en la arquitectura del Estado. Por su parte, los miedos aparecen como una expresión de angustia que tiene sus orígenes en aquello que Segato denomina "patriarcado de bajo impacto" (2013) que se exacerba, con mucha crueldad, desde la modernidad hasta nuestros días. La ciudad homogeniza la vida (Martín-Barbero, 2000), impone y naturaliza estos miedos. Miedo al acoso callejero, miedo a ser violadas, miedo a ser asesinadas, miedo de no volver a nuestras casas. No son un hecho delictivo más, hay una desigualdad histórica fundada en un determinismo biológico simplista y discriminatorio. 
Existen, entonces, diferentes formas de pensar la ciudad y los procesos comunicacionales desde la experiencia de las mujeres teniendo en cuenta las mediaciones y los temores que se presentan en el espacio público.

\section{Imaginación social en clave feminista: nuevas formas de ejercer ciudadanía}

Del apartado anterior surgen los siguientes interrogantes: ¿cómo afrontamos las mujeres estos miedos? ¿Cómo interpelar a los medios desde las mediaciones que construimos?

Para comenzar, una respuesta posible es pensar que en la actualidad muchas mujeres enfrentamos los miedos que nos genera nuestra experiencia en la ciudad a través de lo que Martín-Barbero denomina "vínculos societales" (2002: 11), que se refieren al lazo entre sujetos en el marco de procesos de comunicación de sentido. El feminismo, precisamente, fortalece estos vínculos, que se convierten en mediaciones atravesadas por instancias de vulnerabilidad y resistencia (Butler, 2014). El miedo vulnera pero a la vez configura formas de resistencia.

Martín-Barbero (2000) señala que son los movimientos sociales, entendiendo la relación entre cultura y política, los que permiten profundizar la democracia y la autogestión. Esto promueve nuevas formas de ciudadanía para vencer el miedo. Al respecto Guzmán (2018) indica que un gran aporte que realizó el movimiento feminista fue haber demostrado, a largo plazo, la existencia de recursos fundamentales como las redes, la asociatividad y la perseverancia para que las luchas y demandas se resignifiquen de una generación a otra. Así pues, fueron las sufragistas las que cuestionaron la comprensión de la ciudadanía y, en la actualidad, es el feminismo, en tanto movimiento amplio y heterogéneo, el que vuelve a interpelar las condiciones de ciudadanía para la conquista de derechos.

Sobre el segundo interrogante, consideramos que si bien, muchas reivindicaciones del feminismo no han desaparecido ni mutado, sí ha cambiado la capacidad de generar condiciones de posibilidad para que las agendas de género se implementen. Por lo tanto, las mediaciones construidas en el seno de este movimiento transitan, en la actualidad, nuevas formas de interpelar a los medios tradicionales y los discursos hegemónicos que ellos contienen. Al respecto, se pusieron en evidencia múltiples experiencias de resistencias y luchas invisibilizadas en la agenda mediática que obstruían la recuperación de memorias silenciadas (Carosio, 2017). 
Dicha construcción, tuvo lugar en el marco de la multiplicidad de procesos que genera la globalización (Martín-Barbero, 2002) puesto que a la vez que fragmenta, afianza desigualdades y promueve nuevos escenarios de despliegue neoliberal, también amplía horizontes de transformación y formas de resistencia (Vargas, 2003). Aquí juega un rol fundamental lo que Martín-Barbero define como "imaginación social" (2001: 12) que impulsa nuevos modos de asociación y colaboración cívicas que trascienden las fronteras nacionales.

En el caso que analizaremos con profundidad más adelante, nos encontramos con una experiencia de organización colectiva de periodistas brasileras que buscó poner en evidencia situaciones de acoso por parte de los hinchas durante las coberturas mundialistas. Más de cincuenta profesionales lanzaron una campaña en redes sociales bajo el hashtag \#DeixaElaTrabalhar (DéjalaTrabajar) y viralizaron varios videos donde se mediatizan situaciones de acoso que sufren (manoseos, besos, maltrato, etcétera), por parte de hinchas varones, mientras están trabajando. Esa vulnerabilidad común las invitó a construir lazos de empatía. Así pues, reclaman trabajar en condiciones de igualdad y sanciones para los acosadores.

Las experiencias de miedo en la ciudad, en el trabajo, en los estadios de fútbol que vivimos las mujeres pueden ser afrontadas gracias a los vínculos societales a los que se refiere MartínBarbero que, también, funcionan como estrategias de cuidado compartido. Estas vivencias pueden replicarse a través de la reapropiación de las nuevas tecnologías. Tras la iniciativa de las periodistas deportivas brasileras, también surgió en la Argentina \#PeriodistasUnidas que, bajo el lema "no nos callamos más", busca denunciar el acoso y el machismo en el fútbol, y visibilizar la situación de las mujeres en el mundo deportivo. Nos encontramos en ambos casos con propuestas de imaginación social que generan nuevas construcciones de ciudadanía y fortalecen el desarrollo y ejercicio de derechos adquiridos: transitar libremente y cumplir sus labores en condiciones dignas.

La interconexión transparenta múltiples experiencias de activismo feminista en lo que Vargas define como un "campo de actores" (2003: 201) dinámico y esencialmente heterogéneo abriendo caminos hacia nuevas formas transitar lo colectivo. Estas incipientes formas tienen una gran injerencia en las lecturas que se ejercen del discurso mediático.

En este terreno de interacción entre cultura y poder, muchas mujeres, desde lo que Harcourt y Escobar definen como "políticas del lugar" (2002), ven la oportunidad de construir y deconstruir significados sobre sus cuerpos en los medios de comunicación desde procesos locales. De esta forma, siguiendo a Appadurai (2000), la imaginación capitalista ya no disciplina y controla el cuerpo de las mujeres en los medios puesto que emergen nuevos patrones que cuestionan 
estas formas predatorias (Martín-Barbero, 2002) desde la incidencia de nuevas formas de narrar, incluso en los propios medios.

La movilización a través de las TIC es un factor clave para analizar. La convocatoria "Ni una menos", a nivel nacional, en 2015 y la masiva participación de las mujeres periodistas y comunicadoras en el paro global de mujeres, $8 \mathrm{M}$, marcan una tendencia de solidaridad, intercambio y acción política en diversos territorios. Esto brinda elementos para pensar en la posibilidad de una globalización desde abajo, señalada por Martín-Barbero (2002) tomando aportes de Appadurai, donde la imaginación social es una herramienta fundamental del movimiento feminista para la despatriarcalización de los medios y los miedos.

\section{"La nación somos todos y todas": nuevos sensoriums para pensar la identidad y el fútbol}

A partir del marco de interpretación introducido anteriormente, nos parece oportuno adentrarnos con mayor énfasis al análisis del caso especificado. Para Martín-Barbero una de las expresiones populares que cobraron centralidad a partir de la década del treinta en América Latina, especialmente en nuestro país, es el fútbol. El autor lo destaca como un "gran creador de ídolos y pasiones populares urbanas" (1987: 212) que a su vez generaba identidades. Sin embargo, con el paso de los años podemos ver que esta construcción identitaria ha excluido desde sus inicios a las mujeres como actoras legítimas y creadoras de dicha "pasión popular". Es en nombre de esa misma pasión que el fútbol, en un marco mundialista, se convierte en un espacio donde se exacerba el sentido de una supuesta identidad nacional, en clave masculina y patriarcal, que es reproducida por los medios masivos. Se intenta igualar el fútbol a la nación, cayendo en un intento despolitizado por nombrar(nos) unos a otros y otras. En palabras de Alabarces, este proceso:

Pretende mostrar la nación como un repertorio de consumos, como estilos expresivos, como elecciones estéticas, como afirmaciones pasionales; pero nunca, jamás, como un conjunto de determinaciones ni estructuras, como un conflicto de dominaciones y subalternidades, de intereses contradictorios y opositivos, de clases enfrentadas, de cuerpos sufrientes o gozosos. $Y$ eso es una nación: un repertorio de conflictos, que no se reduce a los resultados de un partido (2007: 209). 
En esta misma línea, el autor plantea que si el lugar para discutir la nación no es el fútbol, ni los medios, entonces debe resolverse en las calles y en la política (2007: 210). Retomaremos más adelante esta idea.

Decíamos que el fútbol históricamente ha sido construido con ethos masculino. Esto tuvo lugar desde las retóricas del espectáculo, en la presentación de las prácticas de algunas mujeres y en las narrativas del periodismo deportivo, donde "las gramáticas de producción que sostienen al discurso futbolístico provienen mayoritariamente del universo masculino" (Binello, Conde, Martínez y Rodríguez, 2000: 33). Del mismo modo, Aráoz Ortiz y Moreira (2013) señalan que, en el periodismo en general, la mujer ocupa un lugar subalterno $y$, de forma particular, en el periodismo deportivo, se da una mayor masculinización de los destinatarios y las destinatarias. La periodista Silvia Ajmat (2018) en su publicación "Mujeres al Mundial: las periodistas que harán historia en Rusia 2018", en el portal del diario La Nación da cuenta de esta predominancia y deja en evidencia que de un total de 222 periodistas de nacionalidad argentina acreditados y acreditadas para la cobertura del último mundial, sólo diez fueron mujeres, es decir, menos del cinco por ciento. Además, no ocuparon roles centrales en la cobertura, sino de acompañamiento y sin posibilidades de emitir opiniones en debates. Sin embargo, el número es histórico ya que nunca se superó dicha cifra en relación a la participación de mujeres trabajando en una cobertura mundialista.

Pese a este escenario hostil, observamos que a diferencia de otros mundiales, en Rusia 2018 emergieron nuevas miradas para pensar al fútbol y su tratamiento en las agendas deportivas y mediáticas que abrieron la posibilidad de cuestionar narrativas en torno a la nación masculina. El fútbol, en tanto práctica popular, se constituye como un espacio de disputa (Martín-Barbero, 1987), donde es posible poner en tensión sentidos dominantes e ir encontrando estrategias para que emerjan otros discursos que cuestionen el modelo único de representar.

Algunas de las experiencias que podemos mencionar en el ámbito nacional son Feminista Mundial, IgualData en conjunto con la Asociación Civil Conectar Igualdad, Cosecha Roja, Página/12, entre otras. De modo general lo que apareció en estas propuestas fue la intención de promover y visibilizar temas que no eran tratados por los principales medios nacionales en sus agendas. Estas iniciativas fueron encontrando pequeños intersticios para romper con los discursos hegemónicos pero bajo una misma excusa: el mundial de fútbol. En términos de De Certeau (2000) lo que se observa es el despliegue de tácticas, es decir, de acciones que trabajan en un escenario adverso. Si bien estas tácticas no cambiaron definitivamente la lógica de funcionamiento mediático, lograron generar ruido y cuestionar vacíos existentes.

A modo de ejemplo, Feminista Mundial se trató de una iniciativa que consistía en transmitir los partidos que disputaba la selección argentina con el relato y comentario de mujeres. 
Posteriormente, se generaban instancias de diálogo donde las periodistas tomaban la palabra para visibilizar, discutir, poner en debate diferentes temáticas que iban desde la problematización de la participación de las mujeres en el deporte en general y en el fútbol en particular, hasta discusiones acerca de la legalización del aborto. En un artículo publicado en la web Emergentes denominado "Feminista Mundial: En primeras personas", las protagonistas toman la palabra y relatan que se trató de una experiencia donde se condensó fútbol y militancia:

"En esta contradicción enorme se amasa la base de Feminista Mundial, la convivencia de espíritus más futboleros, que cruzaban los dedos cuando Messi patea para que entre, y almas más militantes, a las que les cuesta sumarse a la locura mundial, y se angustian a fondo porque Argentina pasó de ronda y hay despidos en TÉLAM. No es que haya un lado y otro, en la mixtura de esas extrañezas encontradas aparece un Bar -La Tribu- una relatora, dos comentaristas, olor y color a fútbol y a coyuntura, ahí se arma una trinchera con aspecto de asamblea".

En este relato y experiencia reaparece el planteo de Alabarces quien cuestiona las narrativas mediáticas hegemónicas que pretenden igualar al fútbol, fundamentalmente a la selección argentina masculina, con la nación (6). Esa concepción de nación imaginada, que siempre tuvo como protagonistas a hombres realizando gestas heroicas, comenzó a ser cuestionadas en este mundial por un movimiento que discute en las calles y luego interpela las agendas. Feminista Mundial, lejos de negar su politicidad, la afirma para repensar también la idea de que el fútbol ya no es "pan y circo", sino es fútbol y militancia.

De nuevo, resulta clave mencionar como común denominador de estas nuevas propuestas el uso de las nuevas tecnologías, principalmente las redes sociales. Observamos cómo el feminismo genera otras mediaciones que, a veces, no tienen visibilidad en los medios tradicionales pero que se viralizan en las redes sociales (Facebook, Twitter, Instagram). Al mismo tiempo, estos vínculos societales, de los que habla Martín-Barbero, encuentran nuevos sentidos a lo "personal es político" y proponen nuevos discursos que van permeando y emergiendo en la disputa por la hegemonía. De esto se trata la construcción de nuevos sensoriums, de nuevas subjetividades, de discontinuidades y continuidades, de nuevas formas de juntarse con otros y otras.

\section{A modo de cierre}


Es la cuestión de cómo recrear las formas de convivencia y deliberación de la vida ciudadana sin reasumir la moralización de los principios, la absolutización de las ideologías y la substancialización de los sujetos sociales; la cuestión de cómo reconstituir las identidades sin fundamentalismos, rehaciendo los modos de simbolizar los conflictos y los pactos desde la opacidad de las hibridaciones, las desposesiones y las reapropiaciones (Martín-Barbero, 1998: 11).

Recrear, reapropiar, reconstruir, resignificar. Los aportes de Martín-Barbero nos invitan a repensar la construcción de ciudadanías, los modos de transitar los miedos y la necesidad de abandonar la racionalidad moderna para librarnos a la conformación de subjetividades desde otro lugar. En ese entramado, que se arma y se desarma permanentemente, nos encontramos con el feminismo como un movimiento social, político y transformador que en los últimos años ha podido rehabitar e interpelar esa ciudad que históricamente expulsó a las mujeres a un mundo privado, invisibilizado, ocultado, subestimado.

Es precisamente ese mismo cuerpo (objeto de permanentes vejaciones) el que busca apoyo en otros cuerpos, en otras redes, lo cual en última instancia, le otorga a los cuerpos de las mujeres una significación política (Butler, 2014).

Aunque no reflexione desde la perspectiva de género, ese nuevo sensorium que MartínBarbero piensa para las juventudes y sus nuevas formas de conocer, de ser, de estar en el mundo a partir de la proliferación de televisión y las nuevas tecnologías (1996) nos brinda pistas para analizar los escenarios actuales fuertemente interpelados por la marea feminista. ¿Qué pasa con las agendas mediáticas en un contexto de conquista de derechos por parte de las mujeres? ¿Cómo se disputan los sentidos en esas agendas? ¿Qué miradas del mundo propone el feminismo que lucha en las calles, pero se desterritorializa en las redes para visibilizar aquello que nos violenta?

Luego de esbozar algunas aproximaciones entre los aportes de Martín-Barbero con la teoría de género, nos detuvimos en reflexionar sobre diferentes situaciones que se dieron recientemente en el marco del Mundial de Fútbol Rusia 2018. La provocación es doble. Por un lado, nos interesó deconstruir los sentidos más arraigados que restringen el fútbol de y para hombres y que en un evento de estas características, global, hipermediatizado y en las lógicas más crueles del capitalismo, pretende instalar narrativas identitarias y nacionales restringidas a una cuestión pasional/despolitizada. Por otro, visibilizar las mediaciones que genera la lucha feminista en las calles y que a partir de las nuevas tecnologías permite deconstruir/construir nuevos sentidos, proponer otros relatos e historias para ejercer nuevas ciudadanías que incluyan a todos y todas. Con Martín-Barbero coincidimos en no centralizar los procesos 
comunicacionales en los medios, para mirar las mediaciones, las experiencias que implican disputas de poder. Allí el feminismo viene siendo central puesto que gestiona nuevas agendas, plantea una criticidad del discurso hegemónico, resignifica el rol de lo colectivo y, permanentemente, promueve la construcción de nuevas redes, de aquella sororidad que nos hermana. De esto que es posible porque "ahora estamos juntas" y "ahora sí nos ven".

\section{Notas}

(1) Ver nota completa en https://bit.ly/2TsflJR

(2) Ver nota completa en https://bit.ly/2se49oo

(3) Ver nota completa en https://bit.ly/2GXfhAx

(4) Los movimientos feministas de la segunda ola se desarrollaron, con diferentes ritmos, significativamente desde los años 60 y 70, pero en la Argentina y en otros países latinoamericanos florece con mayor énfasis en la década del 80, debido a la extrema polarización política y la llegada de las dictaduras.

(5) Virginia Guzmán (24 de agosto de 2018). Feminismos latinoamericanos [Webconferencia]. En el marco del Seminario PRIGEPP Análisis, Programa Regional de Formación en Género y Políticas Públicas (PRIGEPP).

(6) Alabarces sostiene en su revisión de Fútbol y Patria (2007) que el fútbol en tanto "máquina cultural" y operador de nacionalidad pudo y supo construir narrativas nacionalistas con gran pregnancia. Además fue posible articular con otros núcleos para construir narrativas de identidad, por ejemplo, en torno a la clase, a la política, a la edad pero con mayor dificultad en relación al género y a la etnia (Alabarces, 2007: 27).

\section{Bibliografía}

Alabarces, P. (2007). Fútbol y patria. El fútbol y las narrativas de la nación en la Argentina (4ta. ed). Buenos Aires: Prometeo.

Appadurai, A. (1991). La vida social de las cosas. Perspectiva cultural de las mercancías. México: Grijalbo.

Aráoz Ortíz, L. y Moreira, V. (2013). Sobredimensión e invisibilización en el periodismo deportivo. Mujeres y deportes en el diario Olé. Jornadas de Comunicación y Ciencias Sociales, Legados, diálogos, tensiones y desafíos, Buenos Aires.

Binello, G.; Conde, M.; Martínez, A. y Rodríguez, M. G. (2000). Mujeres y fútbol: ¿territorio conquistado o a conquistar? En Alabarces, P. Peligro de Gol. Estudios sobre deporte y sociedad en América Latina. Buenos Aires: CLACSO.

Butler, J. (24 de junio de 2014). Repensar la vulnerabilidad y la resistencia. XV Simposio de la Asociación Internacional de Filósofas, Alcalá de Henares. 
Carosio, A. (2017). Perspectivas feministas para ampliar horizontes del pensamiento crítico y latinoamericano. En Sargot Rodríguez, M. (Coord.). Feminismos, pensamientos críticos y propuestas alternativas en América Latina (pp.17-37). Buenos Aires: CLACSO.

De Certeau, M. (2000). La invención de lo cotidiano I. Artes del hacer. México: Universidad Iberoamericana, Instituto Tecnológico y de Estudios Superiores de Occidente.

Equipo Latinoamericano de Justicia y Género (ELA) (diciembre de 2016). Adolescentes mediatizadas. Buenos Aires.

Harcourt, W. y Escobar, A. (2002). Mujeres y políticas del lugar. México DF: Programa Universitario de Estudios de Género, Universidad Autónoma de México.

Martín-Barbero, J. (1987). De los medios a las mediaciones. Comunicación, cultura y hegemonía. Barcelona: Gili.

Martín-Barbero, J. (1996). Heredando el futuro. Pensar la educación desde la comunicación. Revista Nómadas, 5, Universidad Central Bogotá, Colombia.

Martín-Barbero, J. (1998). Modernidades y destiempos latinoamericanos. Revista Nómadas, 8, Universidad Central, Bogotá, Colombia.

Martín-Barbero J. (2000). La ciudad: entre medios y miedos. Revista Nueva Sociedad Separatas, Caracas, pp. 29-35.

Martín-Barbero, J. (2003). La globalización en clave cultural. Una mirada latinoamericana. Renglones, revista del ITESO, 53, ITESO, Tlaquepaque, Jalisco.

Segato, R. (2013). La crítica de la colonialidad en ocho ensayos. Buenos Aires: Prometeo.

Vargas, V. (2003). Los feminismos latinoamericanos y sus disputas por una globalización alternativa. En Mato, D. (coord.). Políticas de identidades y diferencias sociales en tiempos de globalización (pp. 193- 2017). Caracas: FACES.

\section{Artículos periodísticos}

Vilche, L. (22 de mayo de 2018). No nos callamos más, la pregunta de Yesica Brumec a Sampaoli. La Capital. Recuperado de https://bit.ly/2RwdupZ

Minuto Uno (21 de mayo de 2018). La polémica respuesta de Sampaoli sobre la violencia de género: "Hay cosas difíciles de comprobar". Recuperado de https://bit.ly/2TsflJR

Diario Olé (21 de mayo de 2018). La pregunta que descolocó a Sampaoli. Recuperado de https://bit.ly/2se49oo 
Infobae. (21 de mayo de 2018). Cuál fue la pregunta que más incomodó a Sampaoli en la conferencia de prensa. Recuperado de https://bit.ly/2GXfhAx

Ajmat, S. (28 de mayo de 2018). Mujeres al Mundial: las periodistas que harán historia en

Rusia 2018. La Nación. Recuperado de https://bit.ly/2GWydds

Feminista Mundial (29 de junio de 2018). Feminista Mundial: En primeras personas. Emergentes. Recuperado de https://emergentes.com.ar/feminista-mundial-en-primeraspersonas-37c6e2613b66 